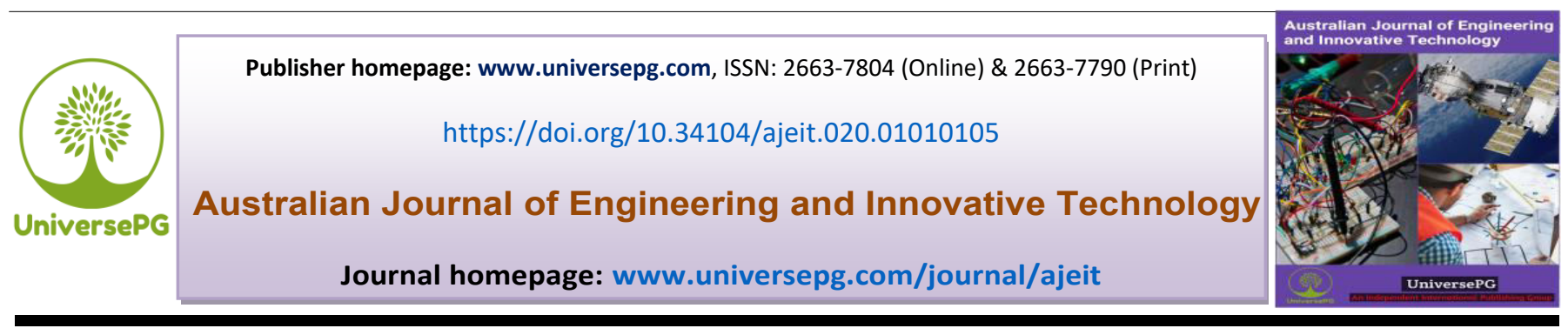

\title{
Monitoring of the Time and Action Calendar of a T-shirt Manufacturing
}

\author{
Faruq Hosen ${ }^{1 *}$, Rezaul Karim¹, Rokibul Islam ${ }^{1}$, Jabir Hossain Babu ${ }^{1}$, Nahidul Islam ${ }^{1}$, Razib Hasan ${ }^{1}$, and \\ SM Abdul Matin ${ }^{1}$ \\ ${ }^{1}$ Department of Textile Engineering, Sonargaon University, Dhaka, Bangladesh. \\ *Correspondence: texfaruq@gmail.com (Faruq Hosen, Lecturer, Department of Textile Engineering, Sonargaon University, \\ Dhaka, Bangladesh).
}

\begin{abstract}
This study was calculated to investigate the time and action (TNA) plan of a T-shirt manufacturing. A time and action calendar determine the final date/time in which the main activities of an order should be against a scheduled distribution window. To ensure timely supply within a specific delivery date of buyers in the knit garments industry, Time and Action Calendar or TNA, a popular tool that is used for tracking and following up in preproduction processes. The acquaintance about the TNA plan will also help to organize the production timeefficient manner that is better production on lead time from buyers. Creating a TNA The calendar doesn't just flow the name and duration of the activity; It's also about technically The duration of the activity works, understandably determining the foregoing and subsequent activities. TNA is the table of activities of specific order and Process flow Sort by the table of tasks that require to be finished. The two key important dates are the cut-off date (PCD) and the ex-factory date as per the TNA plan. TNA largely turned on the order, the prerequisites of the machine, and the specific approach flow of available yield capacity. TNA plan is measured by the time frame which is related to buyers lead time to export a particular order. The TNA obtained by taking it the requisition of 8101 pieces of a basic t-shirt, made out of $95 \%$ cotton and 5\% elastane $160 \mathrm{GSM}$ single jersey fabrics. The order is for SS 2019 and the buyer is GAP, delivery date October 8, 2019, and shipment at New York, USA.
\end{abstract}

Keywords: TNA plan, T-shirt, Manufacturing, Calendar, GSM, Production, Monitoring, and Knit garments.

\section{INTRODUCTION:}

TNA is a popular approach used in the garment manufacturing factory is a strategy to follow and follow important milestones of the preproduction process to confirm timely supply within the scheduled delivery date. Garment Pre-Manufacturing and Merchandising activities. Although some works are depending on each other, others are distinct. Every RMG company occur great care during order planning. Every small detail is built into the planning method. Creating a TNA schedule is not just about entering the name and duration of activities in tabular shapes; it scientifically determines the schedule of the work, logically evaluating the previous and successful activities. TNA schedules have short-term and long-term plans so be careful (Uddin et al., 2020).

Strawberry cutting methods used in the industry use straight knives for straightening cutting and fabric lying in one method is considered as non-invaluable process exclusion in the development of the method only. The 
research department endows with the productive process of cutting. It also decreases the waste of nonproductive activities in the cutting section that can be avoided which can reduce lead time as well as period and space. Therefore, the cutting method in the factory is one of the key values (Jacobs-Blecha, 1993). The cutting zone of the garment manufacturing industry provides the necessary cutting panels in the sewing section for production modules. The cutting panel has several functions in the cutting section like fabric spreading, cutting, numbering and bundling. (Karim et al., 2019; Upendra et al., 2013).

While there are various prices involved in reducing costs by internally wasting costs by a factory, avoiding and upgrading defective work will result in minimal archiving (McClellan et al., 2001; Mohibullah, 2016). The RMG factory has three main sectors namely cutting, sewing, and finishing (Islam et al., 2013).

A TNA schedule is one of the key valuable communication tools that prove that it is effective for this task. The chart made of the time frames (main ones) listed for each work in the plan and these functions require to be carried out in a timely manner. The aim of the TNA is to check at regular intervals, once a week to see if the plan is being implemented adequately. The more smooth the reviews, the sampler it is to accurate the deviation. TNA is commonly effective when a buyer needs to know the current status of an order execution. Usually TNA does not base on the textile used in the product, such as woven or knitted. TNA largely based on the specific approach flow of any order, the requirements of the machine, and the available making capacity. The TNA designed Cutting schedule and the former factory date are two very important dates. Most garment companies open thin manufacturing to upgrade their steps. Progress in timely delivery progress is a field of work that they focus on under the guise of inferiority (Kuma, 2017; Paneru, 2011).

The TNA schedule is one of the key important approaches for managing time. In the field of garment making, each requisition is no less than a new project for the merchant as it involves different functions and use of different resources in different time periods from the time the order is received to the time it is compUniversePG I www.universepg.com leted. Like process numbers, lots of the people are also attached in completing an order. Commonly each order approach and time is same in terms of demand. Thus, a completed plan with properly defined responsibilities is definitely needed to fulfill each order on time. A TNA schedule called the ideal date/period in which the main works of an order should be in contrast to a scheduled distribution window.

This plan sheet is popular as TNA and once a TNA time is created, it can be simple for merchandisers to "make a list" of each day and take it step by step. It can be carrying out on a timely basis to area whether an requisition is on zone as per the TNA schedule or it will be delayed.

\section{MATERIALS AND METHODS:}

\subsection{Materials}

Fabric - In this study work, 95\% cotton and 5\% elastane single jersey textile was used. The fabric GSM (grams per square meter) was 160 , the color was dark blue and deadwood.

Instruments Used - Plain machine, over lock machine, Flat lock machines are used for manufacturing basic tshirt.

\subsection{Methodology}

2.2.1 Part of T-shirt - In knit garments industry t-shirt is common apparel item. These are in followingFrontal side, down side, short and full Sleeves, shoulder joint, etc.

\subsubsection{Different Steps of t-shirt making}

Matching the grade and size range with down and frontal part of sample

Attach the shoulder part<smiles>[AlH2]</smiles>

Insert Interlining

$\downarrow$

Over-lock sewing of the lining

$\downarrow$

Prepare the neck rib and collar

$\downarrow$

Joined the neck rib piping part edge by simple $\mathrm{m} / \mathrm{c}$ 
Making Neck joint

\section{$\downarrow$}

Over-locking of the neck part

Join Neck tape and also attach the size (X, L,

XXL, etc) label

Neck-rib create with top stitch

$\downarrow$

Sewing the main/large label in sample

Sleeve creating and set numbering with the main body parts

Set Sleeve hem

Join Sleeve with the main body part

Sewing arm side hem with body

Side seam join and join the main care label in the bottom side

Prepare Sleeve tuck

Down hem tuck with the end

$\downarrow$

Attached Bottom hem

Final Inspection

\subsubsection{Sketch of t-shirt}
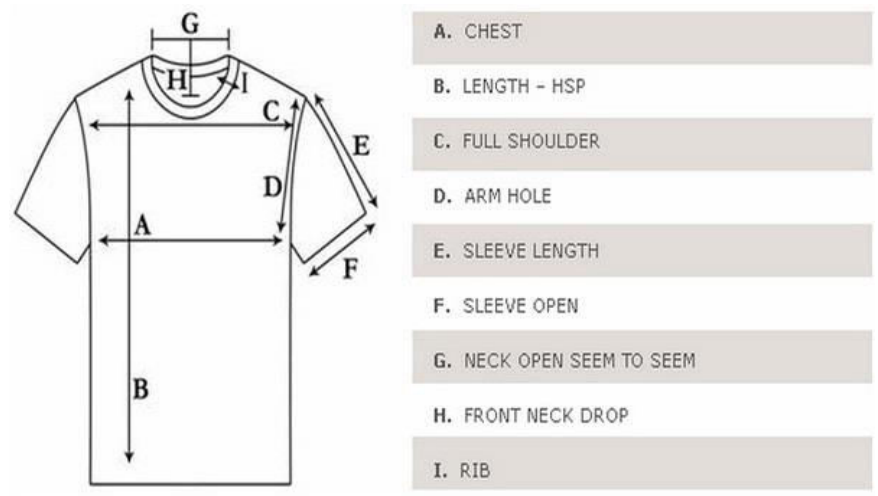

Fig 1: Sketch of t-shirt.

\section{RESULTS AND DISCUSSION:}

TNA plan for the T-shirt making Order in Knit Garments Industry. TNA or T\&A Plan is an important tool for a merchandiser to enlist his day-today activities or to enlist the different operations involved in the method of completing an order.

UniversePG I www.universepg.com
TNA is the key significant work for timely delivery. TNA, a popular approach used in the garment manufacturing factory is a strategy to follow and follow important milestones of the preproduction step to make ensure timely supply within the scheduled delivery date. Garment Pre-Manufacturing and Merchandising works Person in a company have more than one activity character, although some activities are parasite and obey each other, others are individual. Every RMG factory takes great care during order planning.

Table 1: RMG factory activity during order planning

\begin{tabular}{|c|c|c|}
\hline No. & Activity & Planned Date \\
\hline 1 & File \& Sample Receive & $06-07-2020$ \\
\hline 2 & Fabric In-house & 07-07-2020 \\
\hline 3 & Trims In-house Date & $07-07-2020$ \\
\hline 4 & Fabric Inspection Date & $08-07-2020$ \\
\hline 5 & $\begin{array}{c}\text { Shrinkage \& Shade band Done } \\
\text { Date }\end{array}$ & 09-07-2020 \\
\hline 6 & Size range Submission Date & $14-07-2020$ \\
\hline 7 & PPM Done Date & $15-07-2020$ \\
\hline 8 & Pilot run Done Date & $16-07-2020$ \\
\hline 9 & Bulk Cutting Start Date & $17-07-2020$ \\
\hline 10 & Input Date & $18-07-2020$ \\
\hline 11 & Sewing Start Date & $19-07-2020$ \\
\hline 12 & Sewing End Date & $01-10-2020$ \\
\hline 13 & Wash Start Date & $20-09-2020$ \\
\hline 14 & Wash End Date & $02-10-2020$ \\
\hline 15 & Finishing Start Date & $22-09-2020$ \\
\hline 16 & Finishing End Date & 04-10-2020 \\
\hline 17 & Date OF Inspection & 07-10-2020 \\
\hline 18 & $\begin{array}{c}\text { Shipment Sample send to } \\
\text { Buyer }\end{array}$ & $07-10-2020$ \\
\hline 19 & Ex-Factory Date & $08-10-2020$ \\
\hline 20 & Ship CXL Date & $10-10-2020$ \\
\hline
\end{tabular}

Every tiny detail is built into the planning rule. Creating a TNA schedule is not just about entering the name and duration of activities in tabular shapes; it scientifically determines the schedule of the work, logically examining the previous and successful activities. TNA calendars have short-term and long-term 
plans so be careful. A TNA schedule is one of the major significant communication tools that prove that it is effective for this task. The chart made of the time frames (main ones) listed for each work in the plan and these works require to be carried out in a timely manner. The aim of the TNA is to check at regular intervals, once a week to see if the plan is being implemented satisfactorily. TNA is mainly effective when a buyer requires knowing the main status of an order execution.

Merchandisers usually plan the order in a data-sheet, setting the schedule of the main processes in the first column and the planning date for each step in the next column. This plan sheet is popular as TNA and once a TNA plan is created, it can be simple for merchandisers to "make a list" of each day and take it one by one. It can be achieved on a timely based to area whether a requisition is on zone as per the TNA schedule or it will be delayed.

In order to build TNA following mentioned data must be accessible -

Step flow of an requisition with the table of task which require to be done

* Making extent of cutting, packing, sewing, washing, Checking, and finishing

* During sewing lot wise and sample wise capacity

\# Escort time of work, e.g. raw component set time, sampling set time, etc.

Set Shipment schedule, and planned ex-factory time

Usually TNA does not hold on the textile used in the product, such as woven or knitted. TNA largely hang on the desire plan flow of any order, the requirements of the machine, and the available yield capacity. The TNA Plan Cutting time and the former factory date are two very important dates. Before making TNA Plan of knit fabric garments industry, Consequence of numerous Types of Activities knit Garments industry.

3.1 Sampling - Sampling is the key important task and therefore needs to be planned very carefully in TNA, some sampling steps are very necessary so any deviation or late in it will act on the whole TNA.
Example- Proto Samples, Fit Samples, AD/Photo and Shoot/deliveryman garment, Size-Set Sample, GPT Sample, Pilot Run, Pre-Production Meeting and Sample, Production Sample Top.

3.2 Textile and Accessories Sourcing - Textile and accessories sourcing is a very labor intensive step which includes desk weaving and lab-dip approval, accessories and art work approval, FPT consent. Example - Fabric Approval, Trimming and Artwork, and Textile Performance Test.

3.3 Production - The most valuable part of any TNA is the actual production. Many of the time, TNA is pursued with PCD in mind. The sourcing division plays an important role in achieving timely PCD, as the lead period for accessories and textile production and existing for sample made are regulated by this section. Desire lead time and adequate buffer should be kept for sourcing when making TNA.

3.4 Production initiate and end dates - These two dates depend purely on shipment schedule and production capacity. Manufacturing should start as early as the PCD is acquired and the pilot runs and PP samples are approved. Any deviation from this time affects the subsequent top garment submission time and shipment schedule. The period of days needed for production is planned by the capacity assigned to that desired product or the schedule of days available for real shipment date.

\section{CONCLUSION:}

In this study, TNA Plan of knit garments industry was studied. TNA is the most valuable work for timely delivery. If a merchandiser is able to obey the TNA actually, sending the garment as per the schedule will not be a big challenge. Garment making is not a one man show business but a teamwork involving lots of people, companies, suppliers, buyers, sub-contractors and producers. In addition, all work must be done within a certain timeframe for the timely delivery of the garments. TNA plan is helps to execute the whole works in knit garments industry according to lead time. Without TNA plan not possible to execute the buyers order on time. Two TNAs this was also a regular work; one with some of the major key activities proposed by the buyer and the other one with a huge number of 
other internal micro activities (internal activities). It is mandatory to decide that all activities should be in the TNA calendar.

\section{ACKNOWLEDGEMENT:}

The authors gratefully acknowledge the Department of Textile Engineering, Sonargaon University (SU) for technical support of this study.

\section{CONFLICTS OF INTEREST:}

The authors have declared no conflicts of interest to publish the present study.

\section{REFERENCES:}

1) Islam, Md. Mazedul, Khan Adnan Maroof, and Uddin Md. Zulhash. (2013). Elimination of Non Productive Activities is A Must in Cost, and Time Savings in the Sewing Section of Apparel Industry. International Journal of Engineering and Applied Sciences, 1(4): 113-119.

http://eaas-journal.org/otherinfo/Volume-1/546/ $\underline{534}$

2) Jacobs-Blecha, Charlotte, (1993). System Modeling for Apparel Manufacturing; Focus on the Cutting Room. Georgia Institute of Technology G93Nl: 161-164.

3) Karim R, Razzak A, Mahabubuzzaman AKM, and Shahid A. (2019). Comparison of the quality parameter between cotton and melange process, Aust. J. Eng. Innov. Technol., 1(6), 2130. https://doi.org/10.34104/ajeit.019.21030
4) Kuma, B. Shenthil, (2017). Garment Manufacturing through Lean Initiative. Inter-national j. on lean thinking, $\mathbf{3}(2)$ : 1-12.

5) McClellan, Michael et al. (2000). Lean Manufacturing; Tools Techniques and How to Use Them. He St. Lucie Press/APICS Series on Resource Management: 1-245.

6) Mohibullah, A T M. (2016). A Sewing Layout Which Is Enlarged With A Part Of Finishing Can Be More Effective to Cost Reduction Of Apparel Industry. International Journal of Scientific \& Engineering Research, 7(4): 1131-1137. https://www.researchgate.net/publication/30382281 $\underline{7}$

7) Paneru, Naresh, (2011). Implementation of Lean Manufacturing Tools in Garment Manufacturing Process, Pp.1-80.

8) Uddin MM, Karim R, Kaysar MA, Dayan MAR, and Islam KA. (2020). Low-cost jute-cotton and glass fibre reinforced textile composite sheet, Int. J. Mat. Math. Sci., 2(1), 1-7. https://doi.org/10.34104/ijmms.020.01007

9) Upendra, RAS, P Kaluarrachchi, and VS Ratnayake, (2013). Developing a System to Calculate Cutting Process Time of Gar-ments. National engineering conference 2013, $19^{\text {th }}$ Eru Symposium, Faculty of Eng-ineering, University of Moratuwa, Sri Lanka: 26-32.

Citation: Hosen F, Karim R, Islam R, Babu JH, Islam N, Hasan R, and Matin SMA. (2020). Monitoring of the time and action calendar of a T-shirt manufacturing, Aust. J. Eng. Innov. Technol., 2(6), 101-105. https://doi.org/10.34104/ajeit.020.01010105 (C) क्ञ 